\title{
Case Report Orthopaedics
}

\section{TREATMENT OF ANEURYSMAL BONE CYST WITH PERCUTANEOUS SCLEROTHERAPY USING SINGLE DOSE OF POLIDOCANOL : A CASE REPORT}

Harshwardhan Dawar', Anand Ajmera², Alok Verma ${ }^{3}$

1 - Post Graduate, Dept. of Orthopaedics, MGMMC. Indore, MP

2 - Professor, Dept. of Orthopaedics, MGMMC. Indore, MP

3 - Orthopaedics Specialist, Dept. of Orthopaedics, MGMMC. Indore, MP

Corresponding Author

Dr. Harshwardhan Dawar,

Post Graduate Student, Dept. of Orthopaedics, MGMMC. Indore, MP

Address - 4, Jawahar nagar, Retimandi square - 452012 9977574346

\begin{abstract}
Introduction: Aneurysmal bone cyst is a rare benign tumour-like lesion which develops during growth. Percutaneous sclerotherapy is one of the safe alternative to surgery for treatment of aneurysmal bone cysts ( $A B C s$ ) suggested by recent studies. We present our experience of this method involving single dose of the agent.
\end{abstract}

Method And Materials: Our aim was to determine the efficacy of the administration of percutaneous intralesional $3 \%$ polidocanol (hydroxypolyaethoxydodecan) as sclerotherapy in a 7 year old female child with histologically proved aneurysmal bone cyst of proximal tibia, the sclerotherapy was a single dose injection, performed under fluoroscopic guidance under sedation and local anaesthesia, $420 \mathrm{mg}$ of $3 \%$ polidocanol (Approximately $\mathrm{I} \mathrm{ml}$ of $3 \%$ polidocanol was injected per $1 \mathrm{~cm} 3$ volume of the lesion). The follow-up period was 12 months. Radiological and clinical assessments were performed until healing.

Results: The cyst healed after one injection at the time period of 9 months with adequate range of motion and normal functional outcome.
Keywords: Aneurysmal bone cyst, percutaneous sclerotherapy, polidocanol 


\section{Interpretation}

Our results show that percutaneus sclerotherapy with polidocanol has high efficacy in the treatment of $\mathrm{ABCs}$, with a low frequency of side effects. Our findings corroborate data presented in previous publications. We believe that the method will be especially valuable in Aneurysmal Bone Cysts of the tibia, where surgery is associated with considerable morbidity.

Aneurysmal bone cysts (ABCs) are rare expansile osteolytic tumors with an annual incidence of 0.14 per 105 ; they are usually diagnosed at adolescence, and are equally rare in both sexes ${ }^{(1)}$. An eccentrically located, lytic, expansile lesion in the metaphysis with cortical thinning and a subperiosteal thin shell of bone is considered to be typical of an aneurysmal bone cyst. Management includes combinations of embolization, curettage with or without bone grafting, cementing of the cavity, reconstructive surgery, and most recently sclerotherapy ${ }^{(7)}$. Surgical and adjuvant treatment have a high rate of complications. ${ }^{(2-6)}$ Sclerosants act by causing damage to the endothelium of vessels and starting a coagulation cascade that results in thrombosis. The use of polidocanol as an endovenous sclerosing agent to treat varicose veins dates from the 1960s, and has been recently shown to be effective in the treatment of $\mathrm{ABCs}^{(8)}$. In a case series of 72 patients treated with percutaneous intralesional injections of polidocanol $^{(9)}$, a cure rate of $97 \%$ was reported. Similarly, in a prospective study, sclerotherapy was as effective as intralesional excision, but with less morbidity ${ }^{(10)}$. Overall, sclerotherapy has emerged as a promising treatment that could eventually replace previous methods, which may be associated with considerable morbidity.
However, it is not widely accepted and its efficacy remains to be verified in large series of patients. Here we report our experience of percutaneous sclerotherapy of ABC.

\section{Patient and method}

Patient is a 7 year old female child presented to us at MGM Medical college and M.Y. Hopsital, Indore, India with complaints of pain and swelling in her left leg since 2 months, x-ray was suggestive of an osteolytic lesion at the proximal tibia, histopathological examination was suggestive of Anuerysmal bone cyst. Provisional diagnosis was based on the radiological characteristics of the lesion (figure 1) and confirmed with the histological biopsy. The sclerotherapy was a single dose injection, performed under fluoroscopic guidance under sedation and local anaesthesia, by a 16 gauge needle, performed under fluoroscopic guidance under sedation and local anaesthesia by $420 \mathrm{mg}$ of $3 \%$ polidocanol (Approximately 1.2 $\mathrm{ml}$ of $3 \%$ polidocanol was injected per $1 \mathrm{~cm} 3$ volume of the lesion) ${ }^{9}$ by the brand name Asklerol 3\% 2ml by Samarth life sciences pvt. Ltd. (1ml contains $30 \mathrm{mg}$ Polidocanol). Back flow of the sclerosant was prevented by locking the needle for one minute and subsequently flushing it with $0.5 \mathrm{ml}$ of normal saline. Patient was advised to avoid contact sports and strenuous activity until the lesion healed. Patient was allowed normal weight bearing and was followed until the lesion showed evidence of sclerosis and the symptoms subsided (defined as healing).

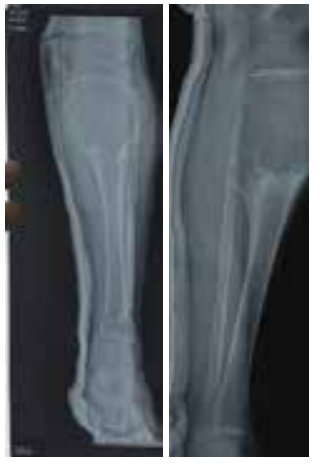

Figure 1 - Lesion

\section{Results}

There was no anaphylaxis, major adverse reactions or minor inflammatory reaction, infection, or local necrosis at the injection site. We did not observe any limb length discrepancy or arrested growth. The patient was allowed to bear weight after 1 week of therapy, following which she continued her routine activities, follow up at 4 weeks showed significant radiological x-ray condensation of the osteolytic tissue and shrinkage in size and less pain, further follow up at 3, 4, 7, 9 months (Figure 2,3,4,5,6) reveal progressive shrinkage in osteolytic tissue size and condensation and no clinical symptoms with free range of motion.

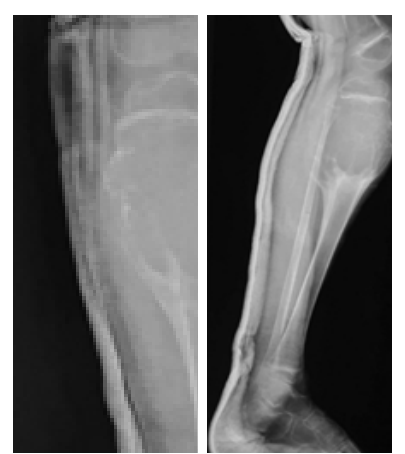

Figure 2 (3 months) 


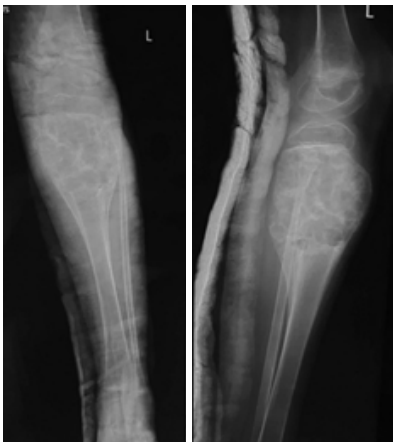

Figure 3(4 months)

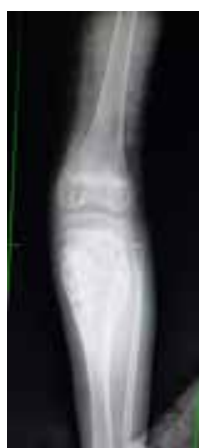

Figure 4 (7 months)

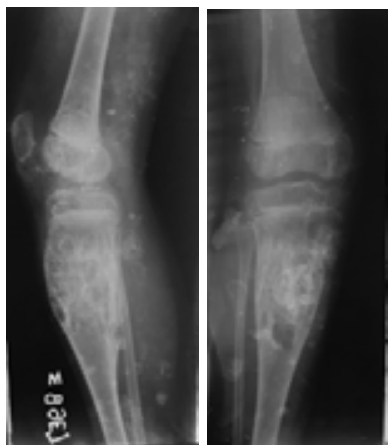

Figure 5 (9 months)

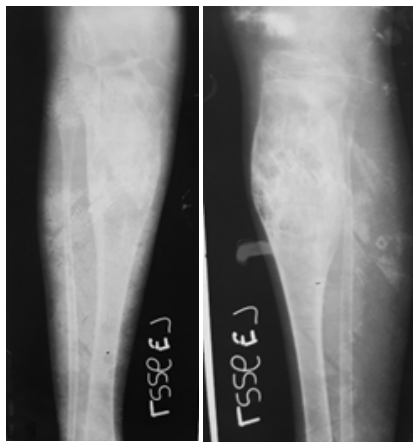

Figure 6 (12 months)

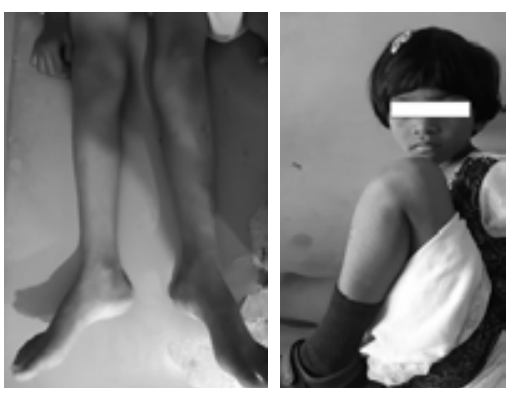

Figure 7 (12 months)

\section{Discussion}

It has been classically considered as an arteriovenous fistula, 1 but some consider it to be posttraumatic 3 in origin and others a de-novo lesion. 4 A venous impedance etiology ${ }^{5}$ has also been proposed. However, most consider it to be some type of vascular malformation, justifying the term 'benign vascular tumour of bone $^{,(2,6,11,12)}$ It may be a primary ${ }^{(13)}$ lesion or superimposed upon another lesion $^{14,15}$ The optimal treatment method for $\mathrm{ABC}$ is still being debated. Open curettage with or without bone grafting is a widely accepted mode of treatment, but it is accompanied by a high recurrence rate of approximately $30 \%$, which can be reduced to $15 \%$ when a high-speed burr is used ${ }^{(10)}$. Wide en-bloc resection gives excellent results in terms of local control, which approximates $100 \%$. Yet, wide surgical margins are often not feasible, as the lesion can be close to neurovascular structures. Furthermore, extensive surgery is associated with considerable morbidity. Cumulative data suggest a growth disturbance rate of about $10 \%$ after various surgical procedures ${ }^{(16,17,18,19)}$. Radiation therapy has also been used, with local control rates that are comparable to those for intralesional therapy ${ }^{(20,21)}$. However, a major concern is the risk of secondary malignancies, especially in the case of younger patients ${ }^{(22)}$. Other potential complications are the possibility of epiphyseal arrest and secondary deformity. The use of highprecision mega-voltage radiotherapy and percutaneous radionuclide ablation has given better results, but is yet to be evaluated in larger series of patients ${ }^{(23,24)}$. Embolization of the feeding arteries has also been suggested as an alternative, with good results reported ${ }^{(25)}$. However, the procedure is technically demanding and is not applicable to all cases, as ABCs often lack large afferent vessels. When used for the treatment of $\mathrm{ABC}$ of the spine, selective angiography is necessary to ensure that there is no risk of spinal cord ischemia. Thus, it is usually regarded as a supplement to surgery ${ }^{(3)}$. Polidocanol sclerotherapy compares favorably with the above treatments. In our hands and also in previous reports ${ }^{(9,10)}$, it has an efficacy exceeding $90 \%$. Furthermore, the treatment is simple and carries negligible risk of morbidity, there is no scar formation, and it can be reliably performed as a day-case surgery. The method is applicable to all cases, and does not require sophisticated technical equipment. Most importantly, sclerotherapy can be effective in the case of lesions of the pelvis and sacrum that are difficult to treat surgically due to the risk of heavy bleeding and other major complications ${ }^{(26)}$ The need for multiple injections and prolonged treatment is an obvious disadvantage which doesn't seems to be the problem with our case which required one injection only. However, prolonged follow-up is also the case for patients treated with surgery, radiotherapy, and embolization as healing of $\mathrm{ABC}$ is generally delayed ${ }^{(10)}$ There is also reported growth disturbances in $4 \%$ of their patients treated with polidocanol (10) We did not observe any such event in our case. The use of polidocanol 
is a definite an advancement over previous sclerotherapy regimens that relied on alcoholic zein solutions, which were more toxic and had serious adverse effects after spillout into nearby tissues ${ }^{(27,28,29)}$. There has been documented fatal outcome after injection in an $\mathrm{ABC}^{(30,31)}$. Indeed, we observed no inflammatory reactions, which is in line with previous studies ${ }^{(9,10)}$. Percutaneous administration of polidocanol should be the standard treatment for $\mathrm{ABC}$, sequential if required, as we have found it to be a safe, simple procedure with an excellent outcome. Further cases of Aneurysmal bone cyst are being treated and followed up at our institute. All data that have accumulated thus far strongly favor sclerotherapy with polidocanol over surgery and suggest that it could become the treatment of choice for $\mathrm{ABC}$.

\section{References}

1. Jaffe H L, Lichtenstein L. Solitary unicameral bone cyst with emphasis on the roentgen picture, the pathologic appearance and the pathogenesis. Arch Surg 1942; 44: $1004-25$

2. Marcove RC, Sheth DS, Takemoto S, Healey $\mathrm{H}$. The treatment of aneurysmal bone cyst. Clin Orthop 1995;311:157-63.

3. Boriani S, De Iure F, Camapanacci L, et al. Aneurysmal bone cyst of the mobile spine: report on 41 cases. Spine 2001;26:27-35.

4. Cole WG. Treatment of aneurysmal bone cysts in childhood. J Pediatr Orthop 1986;6: 326-9.

5. Vergel De Dios AM, Bone JR, Shives TC, McLeod RA, Unni KK. Aneurysmal bone cyst: a clinicopathologic study of 238 cases.Cancer 1992;69:2921-31.

6. Schreuder HW, Veth RP, Prusz- cynski M, et al. Aneurysmal bone cyts treated by curettage, cryotherapy and bone grafting. J Bone Joint Surg [Br] 1997;79-B:20-5.

7. Otsuka T, Kobayashi M, Sekiya I, et al. A new treatment of aneurysmal bone cyst by endoscopic curettage without bone grafting. Arthroscopy 2001;17:28-33.

8. Jain R, Bandhu S, Sawhney S, Mittal R. Sonographically guided percutaneous sclerosis using $1 \%$ polidocanol in the treatment of vascular malformations. J Clin Ultrasound 2002; 30 (7): 416-23

9. Rastogi S, Varshney M K, Trikha V, Khan S A, Choudhury B, Safaya $R$. Treatment of aneurysmal bone cysts with percutaneous sclerotherapy using polidocanol. A review of 72 cases with longterm follow-up. J Bone Joint Surg (Br) 2006; 88 (9): 1212-6

10. Varshney M K, Rastogi S, Khan S A, Trikha V. Is sclerotherapy better than intralesional excision for treating aneurysmal bone cysts? Clin Orthop 2010; (468) (6): 1649-59.

11. Vergel De Dios AM, Bone JR, Shives TC, McLeod RA, Unni KK. Aneurysmal bone cyst: a clinicopathologic study of 238 cases. Cancer 1992;69:2921-31.

12. De Cristofaro R, Biagini R, Boriani $\mathrm{S}$, et al. Selective arterial embolization in the treatment of aneurysmal bone cyst and angioma of bone. Skeletal Radiol 1992;21: 523-7.

13. Enneking WF, Dunham W, Gebhardt MC, Malawer M, Pritchard DJ. A system for the functional evaluation of reconstruction procedures after surgical treatment of tumors of musculo skeletal system. Clin Orthop 1993;286:241-6.

14. Szendroi M, Cser I, Konya A,
Renyi-Vamos. Aneurysmal bone cyst: a review of 52 primary and 16 secondary cases. Arch Orthop Trauma Surg 1992;111:318-22.

15. Martinez V. Sissons HA. Aneurysmal bone cyst: a review of 123 cases including primary lesions and those secondary to other bone pathology.Cancer 1988;61:2291304.

16. Capanna R, Springfield D S, Biagini R, Ruggieri P, Giunti A. Juxtaepiphyseal aneurysmal bone cyst. Skeletal Radiol 1985; 13 (1): 21-5.

17. Green J A, Bellemore M C, Marsden $\mathrm{F}$ W. Embolization in the treatment of aneurysmal bone cysts. J Pediatr Orthop 1997; 17 (4): 440-3.

18. Rizzo M, Dellaero D T, Harrelson J M, Scully S P. Juxtaphyseal aneurysmal bone cysts. Clin Orthop 1999; (364): 205-12.

19. Lampasi M, Magnani M, Donzelli O. Aneurysmal bone cysts of the distal fibula in children: long-term results of curettage and resection in nine patients. J Bone Joint Surg (Br) 2007; 89 (10): 1356-62.

20. Nobler M P, Higinbotham N L, Phillips R F. The cure of aneurysmal bone cyst. Irradiation superior to surgery in an analysis of 33 cases. Radiology. 1968; 90 (6): 1185-92.

21. Feigenberg S J, Marcus R B Jr, Zlotecki R A, Scarborough M T, Berrey B H, Enneking W F. Megavoltage radiotherapy for aneurysmal bone cysts. Int J Radiat Oncol BiolPhys 20011; 49 (5): 1243-7.

22. Marcove R C, Sheth D S, Takemoto $\mathrm{S}$, Healey J H. The treatment of aneurysmal bone cyst. Clin Orthop 1995; (311): 157-63. 
23. Feigenberg $\mathrm{S} J$, Marcus $\mathrm{R} B \mathrm{Jr}$, Zlotecki R A, Scarborough M T, Berrey B H, Enneking W F. Megavoltage radiotherapy for aneurysmal bone cysts. Int J Radiat Oncol BiolPhys 20011; 49 (5): 1243-7.

24. Bush C H, Adler Z, Drane W E, Tamurian R, Scarborough M T, Gibbs $C$ P. Percutaneous radionuclide ablation of axial aneurysmal bone cysts. AJR Am J Roentgenol 2010; 194 (1): W84-90.

25. Amendola L, Simonetti L, Simoes $\mathrm{C} E$, Bandiera S, De Iure F, Boriani S. Aneurysmal bone cyst of the mobile spine: the therapeutic role of embolization. Eur Spine J 2013; 22 (3): 533-41.

26. Brosjö, Otte et al. "Sclerotherapy with polidocanol for treatment of aneurysmal bone cysts" Acta orthopaedica vol. 84,5 (2013): 5025.

27. Falappa P, Fassari F M, Fanelli A, Genovese E, Ascani E, Crostelli M, Salsano V, Montanaro A, Di Lazzaro A, Serra F. Aneurysmal bone cysts: treatment with direct percutaneous Ethibloc injection: long-term results. Cardiovasc Intervent Radiol 2002; 25 (4): 28290 .
28. Adamsbaum C, Mascard E, Guinebretière J M, Kalifa G, Dubousset J. Intralesional Ethibloc injections in primary aneurysmal bone cysts: an efficient and safe treatment. Skeletal Radiol 2003; 32 (10): 559-66.

29. Topouchian V, Mazda K, Hamze B, Laredo J D, Penneçot G F. Aneurysmal bone cysts in children: complications of fibrosing agent injection. Radiology 2004; 232 (2): 522-6.

30. Peraud A, Drake J M, Armstrong D, Hedden D, Babyn P, Wilson G. Fatal ethiblocembolization of vertebrobasilar system following percutaneous injection into aneurysmal bone cyst of the second cervical vertebra. AJNR Am J Neuroradiol 2004; 25 (6): 111620.

31. Gupta G, Pandit R et al. Severe life-threatening hypersensitivity reaction to polidocanol in a case of recurrent aneurysmal bone cyst, Journal of Clinical Orthopaedics and Trauma, 2018, 09765662 